\title{
Traumatic Brain Injury and the Gastrointestinal Tract: The Role of Female Sexual Hormones
}

\author{
Zakieh Keshavarzi ${ }^{\mathrm{a}, \mathrm{b}}$, Amir R. Afsharic ${ }^{\mathrm{c}}$ Nasibeh Mohammadzadeh ${ }^{\mathrm{d}}$, Masoud Mohebbie, f, \\ Moein Mohebbie, Hamid Mollazadeha, b, g
}

\begin{abstract}
Traumatic brain injury (TBI) is an important public health problem which can lead to several complications like gastrointestinal dysfunction. Patients with TBI often suffer from gastrointestinal dysfunctions such as enteral feeding intolerance. Gastric ulceration is induced by various forms of stress like surgery, ischemia and trauma. TBI causes a delayed but significant decrease in intestinal contractile activity in the ileum leading to delayed transport. The association between severity of brain injury and enteral feeding intolerance suggests a strong link between the central nervous system and the non-functional gut. The results of recent basic and clinical studies revealed the beneficial effects of estrogen and progesterone hormones in the treatment of gastrointestinal dysfunction. Females have more resistance to stress and fewer gastrointestinal lesions occur in females as compared to males. Sex steroid hormones have sparked interest as possible neuroprotective agents after traumatic injury and many studies have been done on this subject. This article reviews the literature related to some possible physiological effects of female sexual hormones on the gastrointestinal tract following TBI.
\end{abstract}

Keywords: Female sexual hormones; Traumatic brain injury; Gastrointestinal tract; Estrogen; Progesterone

\section{Introduction}

Traumatic brain injury (TBI) is a noteworthy general medical

Manuscript submitted October 31, 2017, accepted November 15, 2017

aDepartment of Physiology and Pharmacology, School of Medicine, North Khorasan University of Medical Sciences, Bojnurd, Iran

bNatural Products and Medicinal Plants Research Center, North Khorasan University of Medical Sciences, Bojnurd, Iran

'Department of Pharmacology, School of Medicine, Mashhad University of Medical Sciences, Mashhad, Iran

${ }^{\mathrm{d} N e u r o s c i e n c e}$ Research Center, School of Medicine, Mashhad University of Medical Sciences, Mashhad, Iran

eDepartment of Internal Medicine, Imam Reza Hospital, Mashhad University of Medical Sciences, Mashhad, Iran

fEndocrine Research Center, School of Medicine, Mashhad University of Medical Sciences, Mashhad, Iran

'Corresponding Author: Hamid Mollazadeh, Department of Physiology and Pharmacology, School of Medicine, North Khorasan University of Medical Sciences, Bojnurd, Iran. Email: hamidmollazadeh1984@gmail.com

doi: https://doi.org/10.14740/jem466w problem which is regularly joined by hemorrhagic shock. TBI continues to be the most common cause of death for young people and is considered as a significant source of morbidity and death for all ages in developed countries [1]. Current estimates suggest that as many as 5.3 million Americans live with long-term disabilities related to TBI [2]. TBI-induced biomechanical and neurochemical mediated damage, often lead to deficit in cognitive, neuropsychiatric, and physical functions [3-5]. Various forms of traumatic injury are seen worldwide and represent an epidemic condition affecting people of different countries regardless of their level of economic development. Among patients with TBI, gastrointestinal (GI) dysfunction occurs frequently. The association between the severity of brain injury and the intolerance of enteral feeding suggests a strong link between the central nervous system and the nonfunctional gut $[6,7]$. More than $50 \%$ of patients with severe head injuries do not tolerate enteral feedings [8]. The intolerance is presented by vomiting, abdominal distention, delayed gastric emptying [9], esophageal reflux [10], and decreased intestinal peristalsis indicating that GI dysfunction is a common phenomenon following TBI [11].

Usually, acute gastric dilation and postponed gastric emptying are commonly seen in patients with intracranial hypertension, and correction of these gastric abnormalities can help the patients with brain injuries [3]. GI, includes motility abnormality and mucosal alterations that can lead to ulceration, inflammation, and increased gut permeability $[12,13]$.

It is now apparent that sex alters the incidence and outcome of ischemic and traumatic brain injury. Several studies on TBI patients have demonstrated that female sex steroids play neuroprotective roles such as reducing cerebral edema, preventing neuronal loss, and improving functional outcomes [14-16].

Sex hormones, especially estrogens, play a significant role in GI physiology and pathology including regulation of motor and sensory function $[17,18]$. In some studies, it has been reported that steroid hormones, especially progesterone and estrogen, have noticeable effects on the gastric motility and secretions [19] and are also involved in the pathogenesis of some functional disorders of the gut [20].

In recent three decades, numerous researchers have tried to discover the effects of sexual hormones on GI tract following TBI. Based on the female predominance as well as the connection between irritable bowel syndrome (IBS) symptoms and hormonal status, several models have been used to examine the role of sex hormones in GI tract functions including differences in GI symptoms during different phases of the menstrual cycle, in pre- and post-menopausal women, during pregnancy, 


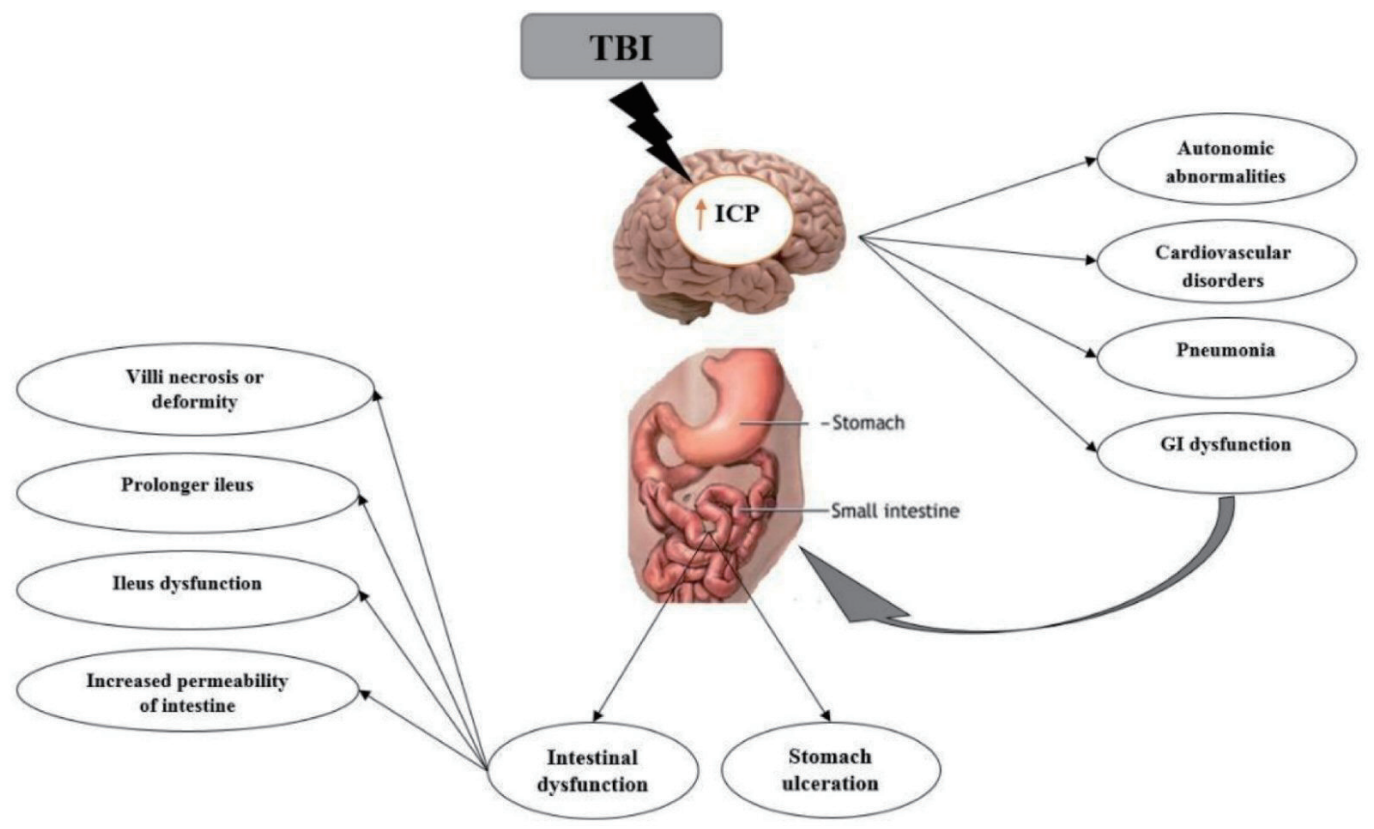

Figure 1. Brain-gut interactions. Some gastrointestinal dysfunction following TBI declared.

and following hormonal treatment or oophorectomy. Consequently, a considerable deal of research was done and compelling evidence indicates sex and gender contribute to the epidemiology, symptomatology, pathophysiology, and treatment outcome. Here, the effects of female sexual hormones on GI tract following TBI were reviewed.

\section{Methods}

Online scientific databases including Medline, PubMed, Science Direct, Scopus, and Google Scholar websites were checked using the terms TBI, cerebral ischemia, GI dysfunction, sex hormones, estrogen and progesterone to identify studies about the effects of female sexual hormones on GI tract following TBI.

\section{TBI and GI Problems}

TBI can lead to significant clinical squeal including pneumonia, cardiovascular disorders, autonomic abnormalities, intestinal dysfunction, multi-system organ failure [21, 22] (e.g. stomach ulceration and gastritis (Cushing's ulcer), prolonged ileus and other motility problems) and most significantly, impairment of gut barrier function [9, 23]. GI dysfunction frequently occurs in patients with TBI and some GI tract disorders experienced during acute stages of stroke are usually considered as stressinduced injuries [24].

Bowel dysfunction is a common complaint among patients with brain damage due to stroke and TBI [25]. Injuries in the brain and its connections can modify individuals' intestinal functioning. Examples of these injuries comprise stroke (cerebrovascular attack (CVA)) and TBI. Brain injury can affect fecal peristalsis and deletion. Immobility, spasticity, muscle weakness, loss of independent bathroom use and the use of some drugs can contribute to bowel dysfunction [25-27].

In one study, the terminal ileum was removed $6 \mathrm{~h}$ following both TBI and sham operation for histologic analysis using hematoxylin and eosin staining. Sham-operated animals had normal-appearing villi with consistent villous height. The histologic appearance of intestinal specimens from TBI animals was notable for marked blunting of intestinal villi with architectural deformity and intestinal villi necrosis [28].

Increased intracranial pressure (ICP) induces immense increases in sympathetic activity, which is responsible for several of the peripheral systemic and GI symptoms [4]. Increased ICP may cause changes in GI motility, water and electrolyte absorption. Studies have examined different means of feeding to brain injured patients as strategies to decrease GI symptoms $[29,30]$.

GI disturbances such as mucosal alterations and motility abnormalities can cause ulceration, inflammation, and increased gut permeability $[9,13]$. The majority of patients with temperate to severe TBI have upper GI intolerance in the first few weeks after injury $[31,32]$. Feighery et al have demonstrated blunting of intestinal villi and increased intestinal permeability, $6 \mathrm{~h}$ following TBI in rats [23] (Fig. 1).

Motility disorders in brain injured patients include gastroesophageal reflux related to reduced tone in the lower esophageal sphincter and deferred gastric emptying [8, 9]. Some studies showed that moderate TBI with no substantial mucosal damage causes a delayed significant decrease in intestinal contractile activity that occurs primarily in the ileum due to decreased contraction amplitude. In addition, intestinal transit was decreased after TBI [33]. Also, studies demonstrated that TBI induces a decrease in both intestinal contractility and transit and an increase in inflammation in the intestinal smooth muscle suggesting that motility is inhibited in the small intes- 
tine due to inflammatory damage secondary to the brain injury. Inflammation of the mucosal layer of the small intestine, leading to increased permeability, has been demonstrated suggesting inflammatory damage to the small intestine [13, 34]. Hang et al have also shown histopathologic changes and increased permeability in gut as early as $2 \mathrm{~h}$, peaking at $24 \mathrm{~h}$ following TBI [13].

In a study, contractile activity was examined in ileal segments of the small intestine in sham and TBI groups 1, 3 and 7 days post surgery. This study showed that motility in the small intestine is also affected by TBI. Contractile dysfunction was mainly limited to the distal small intestine. Contractile activity was considerably decreased in the TBI group 7 days post injury compared to the sham group. TBI was scanned using a computed tomography (CT) scanner and volume loss due to TBI was calculated. Following TBI, there is neuronal loss due to necrosis and apoptosis in the damaged area. This is followed by a delayed secondary loss of neurons in the area surrounding the injury site due to apoptosis [33].

Decreased intestinal contractile activity may contribute to the symptoms of vomiting and abdominal distension described in TBI patients. Altered contractile activity and motility in the small intestine were associated with increased inflammation in the intestinal smooth muscle [33].

\section{Sex Hormones and TBI}

The majority of available data suggest that $17 \beta$-estradiol (E2) protects against apoptotic cell death, and this is maybe mediated through mitochondrial anti-apoptotic mechanisms, as some studies investigating estrogen in central nervous system (CNS) trauma have reported favorable modulation of $\mathrm{Bcl}$ family proteins [35]. Sex steroid hormones have sparked interest as possible therapeutic agents following TBI. Estrogen or progesterone alone or a combination of these two hormones, reduces brain edema following TBI $[36,37]$. E2 or G-protein coupled estrogen receptor 1 (GPER)-specific agonist, G-1, increases cell survival and decreases neuronal degeneration, apoptosis, and astrogliosis. The anti-inflammatory properties of estrogen or progesterone alone or in combination reduce brain edema and permeability of the blood-brain barrier following TBI [36], and these effects were associated with changes in pro-inflammatory cytokines concentrations [38, 39]. Among numerous interactions between sex hormones and other neurotransmitters, estrogen interactions and serotonin and corticotropin-releasing factor (CRF) signaling systems play a pivotal role $[40,41]$. Estrogens can also modulate neuro-immune interactions triggered by stress via the brain-gut axis [42].

\section{TBI, GI Tract and Sex Hormones}

Numerous studies have suggested the protection role of estrogen and progesterone in the development of a variety of diseases, including cardiovascular diseases [43], cerebral damage, fatality [44], and osteoporosis [43, 45, 46]. Also, previous studies have shown that peptic ulcer is more common in men than women. Therefore, it is rational to infer that, similar to other organs, E2 and progesterone may have protective effects in GI tract, and E2 plays a protecting role against acid-peptic duodenal injury in females [47]. Steroid hormones, in particular progesterone and estrogen, have effects on the gastric motility and secretions [19], and are also involved in the pathogenesis of some functional disorders in the gut [20]. This might provide a sensible explanation for the clinically observed gender difference in the prevalence of duodenal ulcer (Table 1 [48-62]).

Keshavarzi et al have shown that protective effect of estradiol and a combination of E2 and progesterone (P4) against mucosal damage after TBI might be mediated by inhibition of pepsin secretion. In this study, gastric pepsin levels were increased in sham-operated animals as compared to intact group. Gastric pepsin levels were considerably lower in E2 alone and E2 and P4-treated rats as compared to vehicle-treated group. These results suggest that the possible protective effect of estradiol and E2-P4 combination against mucosal injury after TBI might be mediated by inhibition of pepsin secretion [63].

The results demonstrated that a reduction of pepsin secretion in pregnancy, when the concentration of ovarian hormones is high [64], a decrease in pepsin secretion induced by ovarian hormones in rats [65], inhibition of pepsin secretion in ovariectomized (OVX) rats by estradiol [66], and an increase in pepsin secretion followed by gastric mucosal inflammation after stress [67].

Peptic duodenal and gastric ulcers raise serious health problems and significant economic burden worldwide [1]. Gender differences in duodenal ulcer have been clinically observed for many years; however, little is known about the causes and underlying mechanisms [68-70]. Due to the fact that estrogen is a hormone mainly present in the female body and, in comparison to men, women of reproductive ages also experience a significantly lower occurrence of duodenal ulcer [71, 72]. Studies have shown that pregnant women or women taking oral contraceptive pills (estrogen/progesterone compounds) exhibited a reduced frequency of duodenal ulcer [73]. Furthermore, duodenal ulcer runs a more serious course in postmenopausal than premenopausal women [47]. Finally, clinical observations showing that pregnant women with high estrogen levels of placental origin hardly develop ulcers and women taking oral contraceptives experience a significantly decreased incidence of ulcers [73], strongly support the protective role of estrogen in the duodenum [3].

Keshavarzi and Khaksari examined the alteration of gastric function and barrier function of GI tract following diffuse brain injury in different ovarian hormone status. In this study, diffuse TBI was induced by Marmarou's method. Rats were randomly assigned into 10 groups: Intact, sham + ovariectomized female (OVX), TBI, TBI + OVX, vehicle, estradiol (E2), progesterone $(\mathrm{P}), \mathrm{E} 2+\mathrm{P}$, estrogen receptor alpha agonist and estrogen receptor beta agonist (DPN). Endotoxin levels were measured using enzyme-linked immunosorbent assay method. They found that pretreatment with sexual steroids is not useful in the treatment of GI dysfunction induced by TBI and treatment with all sexual female hormones worsened gastric tissue condition. Furthermore, the applied weight was not enough for releasing of endotoxin. It seems that estrogen re- 
Table 1. The Relationships Between Traumatic Brain Injury, Sex Hormones Status and Gastrointestinal Tract and Their Underlying Mechanisms

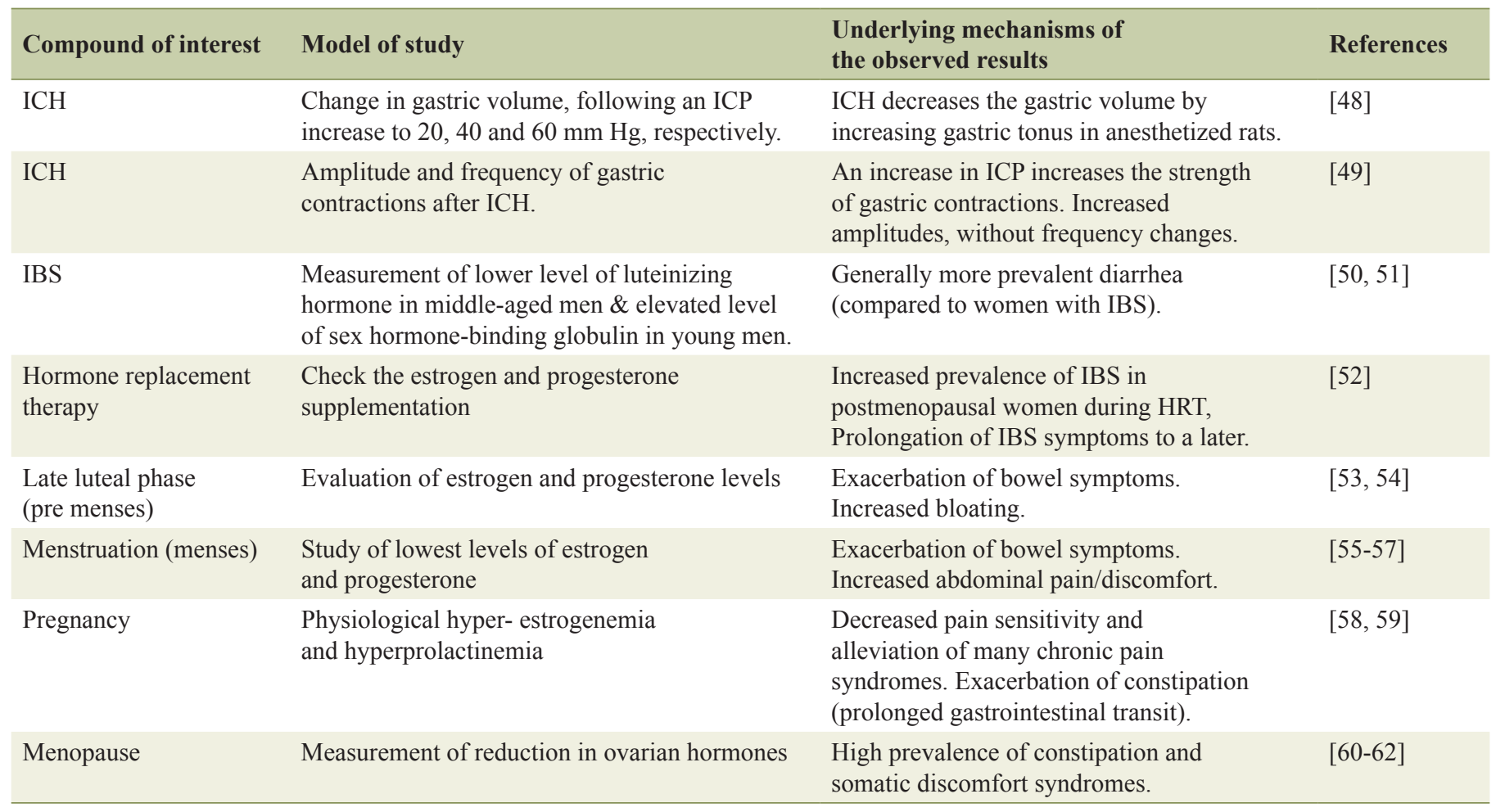

IBS: irritable bowel syndrome; HRT: hormone replacement therapy; ICH: intracranial hypertension; ICP: intracranial pressure.

duced endotoxin levels via estrogen beta receptor [74].

The role of gonadal hormones, in symptomatology and pathophysiology of IBS is being recognized based on the female predominance as well as the relation between IBS symptoms and hormonal status during menstrual cycle phases, pregnancy or menopause [75]. IBS is a GI sensory-motor disorder characterized by abdominal pain or discomfort linked with changes in bowel habits [59]. Li et al noted that the expression of 5-HT3 receptor mRNA was considerably decreased in rats after $\mathrm{E} 2+\mathrm{P}$ treatment as compared to sham-treated ovariectomized rats that often coexist with IBS [76]. Women with IBS are likely to experience an increase in abdominal pain and bowel symptoms at a time of declining or low ovarianhormone levels. Dourado et al demonstrated that, in patients with brain injury because of stroke and TBI, bowel dysfunction is frequent, especially in patients with motor difficulties communication impairment and memory disorder [25]. Furthermore, it was shown that the prevalence of IBS subtypes vary according to gender [77]. Women with IBS, compared to male patients, are more likely to report constipation, bloating, severe abdominal pain, and feeling of incomplete evacuation, while men with IBS more often complain of diarrhea-associated symptoms [77-79]. The results of epidemiological studies and clinical views confirm significant effect of sex and gender differences on IBS prevalence and symptomatology. Moreover, a growing number of clinical and experimental studies strongly support the crucial role of sex hormones in the regulative mechanisms of the brain-gut-microbiota axis involved in the pathophysiology of IBS. Sex hormones may influence on the peripheral and central regulatory mechanisms such as contributing the alterations in stress reaction, visceral sensitivity and motility, intestinal barrier function, and immune activation of intestinal mucosa [63].

The relationships between gonadal hormones and somatic and visceral pain sensibility in humans are complex. E2 and progesterone may play both anti-nociceptive and pro-nociceptive roles, depending on their relative density as well as the duration of presentation. The results of a study done by Khaksari et al have shown that progesterone has no effect on intestinal cytokines, and when used in combination with estradiol, the effect of estradiol was also eliminated. They concluded that progesterone may interfere with the action of estrogen on the levels of intestinal cytokines [74].

Research analyzing post-TBI intestines and serum has shown the importance of a local inflammatory reaction, mediated in part by an increase in intestinal concentrations of cytokines such as tumor necrosis factor (TNF)- $\alpha$ and interleukin (IL)- 6 [80]. Studies have shown that increased levels of TNF- $\alpha$ as well as IL- $1 \beta$ and IL-6 production [81] associated with higher intestinal permeability following TBI $[82,83]$. It is now obvious that gender alters the outcome of TBI.

Previous studies showed that pregnancy can decrease the symptoms of rheumatoid arthritis and inflammatory bowel disease [84], and estradiol can reduce the production of inflammatory cytokines such as IL-6 and TNF- $\alpha$ [85]. Estradiol has been found to have anti-inflammatory activity in GI, through 
reduction of neutrophil leakage and cytokine production in colitis [86]. Estradiol can also inhibit cytokine production via an NFאB-dependent mechanism [87]. Mizushima et al have reported that administration of estradiol to rats after a period of shock/hemorrhage decreased plasma levels of IL-6 and improved cardiac and liver function [88]. Also, estradiol has been shown to reduce intestinal levels of IL-6 following traumahemorrhage [89]. TNF- $\alpha$ and IL-6 form a complete feedback loop whereby TNF- $\alpha$ induces IL-6 synthesis and IL-6, in turn, inhibits TNF- $\alpha$ production.

Telleria et al reported that progesterone can efficiently inhibit the expression of IL-6 in the corpus luteum [90]. Lan et al revealed that progesterone reduced the consistency of IL- $1 \beta$ mRNA [91], and Pioli et al reported that estradiol decreased IL-8 production in monocytes. It has been also shown that estrogen increased intestinal levels of IL- 6 and IL-1 $\beta$ following TBI [85]. Hang et al have shown that intestinal levels of TNF- $\alpha$ and IL-6 considerably increased after brain trauma [80]. Also, Brzozowski et al have shown that serum IL-1 $\beta$ increased after ischemia-reperfusion damage [92]. The results of Khaksari et al have shown that estradiol decreased intestinal levels of TNF- $\alpha$, progesterone decreased serum levels of TNF- $\alpha$ and estrogen influenced intestinal levels of pro-inflammatory cytokines, especially TNF- $\alpha$, which is probably mediated through estrogen receptor [93]. Chen et al found that intestinal levels of TNF- $\alpha$, IL-1 $\beta$, and IL-6 significantly increased following brain trauma [82]. Khaksari et al have shown that TBI induced an increase in intestinal-1 $\beta$, IL-6, and TNF- $\alpha$ levels as well as serum levels of IL-1 $\beta$ [93].

Other studies have shown that levels of TNF- $\alpha$ in intestinal segments exposed to acidosis and hypoxia are higher in men than women. Also, menopause is thought to be linked with increased production of inflammatory cytokines like ILs and TNF- $\alpha$, as increased levels of inflammatory cytokines have been seen in postmenopausal women [94].

Some studies have shown that the beneficial effects of $17 \beta$-estradiol on inflammatory cytokine production following trauma hemorrhage are dependent on the tissue compartment as this effect is mediated by endoplasmic reticulum (ER) in Kupffer cells and splenic macrophages and by ER- $\beta$ in alveolar macrophages [95].

Some of the possible mechanisms underlying the activity of these hormones against ulcerative effects of traumatic brain injuries are: maintaining calcitonin gene relevant peptide (CGRP) level, that has the protective role in mucosal injuries [96], over-production of mucosal secretion by gastric mucosal [17], the increase of bicarbonate secretion from gastric mucosal like to the increased secretion of bicarbonate from duodenum mucosal by estrogen [47], alteration of hypothalamic pituitary axis (HPA) is response to stress [86], the reduction of vascular epidermal growth factor (VEGF) secretion in stomach [97], inhibition of oxidative stress [98], modulation of nitric oxide (NO) production [99], regulation of autonomic nervous system activity [100], interaction with melatonin in gastric mucosal level [101], promotion of angiogenesis [102], reduction of gastric inflammation by decreasing TNF- $\alpha$ release [103], and inhibition of apoptosis due to ischemia [104].

In the present review, we studied the effects of estrogen and progesterone on GI tract following TBI. The results of epidemiological and clinical studies showed the significant role of female sexual hormones in sex and gender differences. Furthermore, a growing number of clinical and experimental studies strongly support the crucial role of sex hormones in regulation of the brain-gut axis [105]. Some discrepancies in the results may result from different experimental conditions or heterogeneous groups of patients (e.g. different age, different status), but they also reflect the very complex nature of sex hormone actions.

\section{Conclusions}

In summary, TBI can lead to several physiological complications including chronic GI dysfunction and may cause a delayed but significant reduction of intestinal contractile activity mainly in the distal intestine. Specifically, TBI can induce an increase in intestinal permeability, which may lead to bacterial translocation, sepsis, and finally multi-system organ failure. However, the exact mechanism of increased intestinal permeability following TBI is unknown.

According to the available data, that administration of estrogen alone or co-administration of estrogen and progesterone has an inhibitory effect on the pepsin production. These results suggest that the possible protecting effect of ovarian hormones against mucosal injure induced by TBI is mediated by inhibition of pepsin secretion and not via acid secretion. However, the real fluctuations in ovarian hormones may influence peripheral and central regulatory mechanisms of the brain-gut axis involved in the pathophysiology of IBS contributing to the alterations in visceral sensibility motility, intestinal barrier function, and immune activation of intestinal mucosa.

Therefore, female sexual hormones can have some effects on the GI tract following TBI. However, further investigations (both clinical and experimental) are required to reveal the exact perspectives of their constituents effects.

\section{Acknowledgments}

This study was partially supported by the North Khorasan University of Medical Sciences.

\section{Conflict of Interest}

The authors declare no conflict of interest.

\section{References}

1. Kauvar DS, Lefering R, Wade CE. Impact of hemorrhage on trauma outcome: an overview of epidemiology, clinical presentations, and therapeutic considerations. J Trauma. 2006;60(6 Suppl):S3-11.

2. Coronado VG, Xu L, Basavaraju SV, McGuire LC, Wald MM, Faul MD, Guzman BR, et al. Surveillance for traumatic brain injury-related deaths - United States, 1997- 
2007. MMWR Surveill Summ. 2011;60(5):1-32.

3. Lucena AF, Tiburcio RV, Vasconcelos GC, Ximenes JD, Cristino Filho G, Graca RV. Influence of acute brain injuries on gut motility. Rev Bras Ter Intensiva. 2011;23(1):96-103.

4. McAllister TW. Neurobiological consequences of traumatic brain injury. Dialogues Clin Neurosci. 2011;13(3):287-300.

5. Bernabeu M, Demirtas-Tatlidede A, Opisso E, Lopez R, Tormos JM, Pascual-Leone A. Abnormal corticospinal excitability in traumatic diffuse axonal brain injury. J Neurotrauma. 2009;26(12):2185-2193.

6. Jackson MD, Davidoff G. Gastroparesis following traumatic brain injury and response to metoclopramide therapy. Arch Phys Med Rehabil. 1989;70(7):553-555.

7. Pilitsis JG, Rengachary SS. Complications of head injury. Neurol Res. 2001;23(2-3):227-236.

8. Norton JA, Ott LG, McClain C, Adams L, Dempsey RJ, Haack D, Tibbs PA, et al. Intolerance to enteral feeding in the brain-injured patient. J Neurosurg. 1988;68(1):62-66.

9. Kao $\mathrm{CH}$, ChangLai SP, Chieng PU, Yen TC. Gastric emptying in head-injured patients. Am J Gastroenterol. 1998;93(7):1108-1112.

10. Saxe JM, Ledgerwood AM, Lucas CE, Lucas WF. Lower esophageal sphincter dysfunction precludes safe gastric feeding after head injury. J Trauma. 1994;37(4):581-584; discussion 584-586.

11. Pedoto MJ, O’Dell MW, Thrun M, Hollifield D. Superior mesenteric artery syndrome in traumatic brain injury: two cases. Arch Phys Med Rehabil. 1995;76(9):871-875.

12. Bansal V, Ryu SY, Blow C, Costantini T, Loomis W, Eliceiri B, Baird A, et al. The hormone ghrelin prevents traumatic brain injury induced intestinal dysfunction. J Neurotrauma. 2010;27(12):2255-2260.

13. Hang CH, Shi JX, Li JS, Wu W, Yin HX. Alterations of intestinal mucosa structure and barrier function following traumatic brain injury in rats. World J Gastroenterol. 2003;9(12):2776-2781.

14. Roof RL, Duvdevani R, Stein DG. Gender influences outcome of brain injury: progesterone plays a protective role. Brain Res. 1993;607(1-2):333-336.

15. Wright DW, Bauer ME, Hoffman SW, Stein DG. Serum progesterone levels correlate with decreased cerebral edema after traumatic brain injury in male rats. J Neurotrauma. 2001;18(9):901-909.

16. Won CK, Kim MO, Koh PO. Estrogen modulates Bcl-2 family proteins in ischemic brain injury. J Vet Med Sci. 2006;68(3):277-280.

17. Hogan AM, Collins D, Baird AW, Winter DC. Estrogen and its role in gastrointestinal health and disease. Int $\mathrm{J}$ Colorectal Dis. 2009;24(12):1367-1375.

18. Ji Y, Tang B, Traub RJ. The visceromotor response to colorectal distention fluctuates with the estrous cycle in rats. Neuroscience. 2008;154(4):1562-1567.

19. Bradesi S, Eutamene H, Fioramonti J, Bueno L. Acute restraint stress activates functional NK1 receptor in the colon of female rats: involvement of steroids. Gut. 2002;50(3):349-354.

20. Mathias JR, Clench MH. Relationship of reproductive hormones and neuromuscular disease of the gastrointestinal tract. Dig Dis. 1998;16(1):3-13.

21. Osborn TM, Tracy JK, Dunne JR, Pasquale M, Napolitano LM. Epidemiology of sepsis in patients with traumatic injury. Crit Care Med. 2004;32(11):2234-2240.

22. Kemp CD, Johnson JC, Riordan WP, Cotton BA. How we die: the impact of nonneurologic organ dysfunction after severe traumatic brain injury. Am Surg. 2008;74(9):866872.

23. Feighery L, Smyth A, Keely S, Baird AW, O'Connor WT, Callanan JJ, Brayden DJ. Increased intestinal permeability in rats subjected to traumatic frontal lobe percussion brain injury. J Trauma. 2008;64(1):131-137; discussion 137-138.

24. Kawakubo K, Fujishima M. [Management of gastrointestinal mucosal damage in patients with cerebrovascular disease]. Nihon Rinsho. 2002;60(8):1573-1579.

25. Dourado CC, Engler TMNdM, Oliveira SBd. Bowel dysfunction in patients with brain damage resulting from stroke and traumatic brain injury: A retrospective study of a case series. Texto \& Contexto-Enfermagem. 2012;21(4):905-911.

26. Coggrave M, Wiesel PH, Norton C. Management of faecal incontinence and constipation in adults with central neurological diseases. Cochrane Database Syst Rev. 2006;2:CD002115.

27. Coggrave M, Norton C, Cody JD. Management of faecal incontinence and constipation in adults with central neurological diseases. Cochrane Database Syst Rev. 2014; 1:CD002115.

28. Bansal V, Costantini T, Kroll L, Peterson C, Loomis W, Eliceiri B, Baird A, et al. Traumatic brain injury and intestinal dysfunction: uncovering the neuro-enteric axis. $\mathrm{J}$ Neurotrauma. 2009;26(8):1353-1359.

29. Rapp RP, Young B, Twyman D, Bivins BA, Haack D, Tibbs PA, Bean JR. The favorable effect of early parenteral feeding on survival in head-injured patients. J Neurosurg. 1983;58(6):906-912.

30. Hartl R, Gerber LM, Ni Q, Ghajar J. Effect of early nutrition on deaths due to severe traumatic brain injury. J Neurosurg. 2008;109(1):50-56.

31. Krakau K, Omne-Ponten M, Karlsson T, Borg J. Metabolism and nutrition in patients with moderate and severe traumatic brain injury: A systematic review. Brain Inj. 2006;20(4):345-367.

32. Tan M, Zhu JC, Yin HH. Enteral nutrition in patients with severe traumatic brain injury: reasons for intolerance and medical management. Br J Neurosurg. 2011;25(1):2-8.

33. Olsen AB, Hetz RA, Xue H, Aroom KR, Bhattarai D, Johnson E, Bedi S, et al. Effects of traumatic brain injury on intestinal contractility. Neurogastroenterol Motil. 2013;25(7):593-e463.

34. Wang YB, Liu J, Yang ZX. Effects of intestinal mucosal blood flow and motility on intestinal mucosa. World J Gastroenterol. 2011;17(5):657-661.

35. Day NL, Floyd CL, D’Alessandro TL, Hubbard WJ, Chaudry IH. 17beta-estradiol confers protection after traumatic brain injury in the rat and involves activation of $\mathrm{G}$ protein-coupled estrogen receptor 1. J Neurotrauma. 
2013;30(17):1531-1541.

36. Shahrokhi N, Khaksari M, Soltani Z, Mahmoodi M, Nakhaee N. Effect of sex steroid hormones on brain edema, intracranial pressure, and neurologic outcomes after traumatic brain injury. Can J Physiol Pharmacol. 2010;88(4):414-421.

37. Soltani Z, Khasksari M, Shahrokhi N, Nakhaei N, Shaibani V. Effect of combined administration of estrogen and progesterone on brain edema and neurological outcome after traumatic brain injury in female rats. Iran J Endocrinol Metab. 2009;10(6):629-638.

38. Khaksari M, Soltani Z, Shahrokhi N, Moshtaghi G, Asadikaram G. The role of estrogen and progesterone, administered alone and in combination, in modulating cytokine concentration following traumatic brain injury. Can J Physiol Pharmacol. 2011;89(1):31-40.

39. Sarkaki AR, Khaksari Haddad M, Soltani Z, Shahrokhi N, Mahmoodi M. Time- and dose-dependent neuroprotective effects of sex steroid hormones on inflammatory cytokines after a traumatic brain injury. J Neurotrauma. 2013;30(1):47-54.

40. Rybaczyk LA, Bashaw MJ, Pathak DR, Moody SM, Gilders RM, Holzschu DL. An overlooked connection: serotonergic mediation of estrogen-related physiology and pathology. BMC Womens Health. 2005;5:12.

41. Tache Y, Bonaz B. Corticotropin-releasing factor receptors and stress-related alterations of gut motor function. J Clin Invest. 2007;117(1):33-40.

42. Cremon C, Gargano L, Morselli-Labate AM, Santini D, Cogliandro RF, De Giorgio R, Stanghellini V, et al. Mucosal immune activation in irritable bowel syndrome: gender-dependence and association with digestive symptoms. Am J Gastroenterol. 2009;104(2):392-400.

43. Orshal JM, Khalil RA. Gender, sex hormones, and vascular tone. Am J Physiol Regul Integr Comp Physiol. 2004;286(2):R233-249.

44. Zhang Y, Champagne N, Beitel LK, Goodyer CG, Trifiro M, LeBlanc A. Estrogen and androgen protection of human neurons against intracellular amyloid beta142 toxicity through heat shock protein 70 . J Neurosci. 2004;24(23):5315-5321.

45. Popp AW, Bodmer C, Senn C, Fuchs G, Kraenzlin ME, Wyss H, Birkhaeuser MH, et al. Prevention of postmenopausal bone loss with long-cycle hormone replacement therapy. Maturitas. 2006;53(2):191-200.

46. Gozansky WS, Van Pelt RE, Jankowski CM, Schwartz RS, Kohrt WM. Protection of bone mass by estrogens and raloxifene during exercise-induced weight Loss. J Clin Endocrinol Metab. 2005;90(1):52-59.

47. Smith A, Contreras C, Ko KH, Chow J, Dong X, Tuo B, Zhang HH, et al. Gender-specific protection of estrogen against gastric acid-induced duodenal injury: stimulation of duodenal mucosal bicarbonate secretion. Endocrinology. 2008;149(9):4554-4566.

48. Cristino-Filho G, Leal PR, Lira GH, Souza SG, Rola FH, Oliveira RB, Souza MA, et al. Acute intracranial hypertension increases gastric tonus in anesthetized rats. Auton Neurosci. 2009;146(1-2):95-101.

49. Livingston EH, Passaro EP, Jr., Garrick T. Elevated in- tracranial pressure stimulates gastric contractility in the rat. J Surg Res. 1991;50(2):106-110.

50. Houghton LA, Jackson NA, Whorwell PJ, Morris J. Do male sex hormones protect from irritable bowel syndrome? Am J Gastroenterol. 2000;95(9):2296-2300.

51. Kim BJ, Rhee PL, Park JH, Chang DK, Kim YH, Son HJ, Kim JJ, et al. Male sex hormones may influence the symptoms of irritable bowel syndrome in young men. Digestion. 2008;78(2-3):88-92.

52. Ruigomez A, Garcia Rodriguez LA, Johansson S, Wallander MA. Is hormone replacement therapy associated with an increased risk of irritable bowel syndrome? Maturitas. 2003;44(2):133-140.

53. Farage MA, Neill S, MacLean AB. Physiological changes associated with the menstrual cycle: a review. Obstet Gynecol Surv. 2009;64(1):58-72.

54. Moore J, Barlow D, Jewell D, Kennedy S. Do gastrointestinal symptoms vary with the menstrual cycle? $\mathrm{Br} \mathrm{J}$ Obstet Gynaecol. 1998;105(12):1322-1325.

55. Chang L, Lee OY, Naliboff B, Schmulson M, Mayer EA. Sensation of bloating and visible abdominal distension in patients with irritable bowel syndrome. Am J Gastroenterol. 2001;96(12):3341-3347.

56. Houghton LA, Lea R, Jackson N, Whorwell PJ. The menstrual cycle affects rectal sensitivity in patients with irritable bowel syndrome but not healthy volunteers. Gut. 2002;50(4):471-474.

57. Ouyang A, Wrzos HF. Contribution of gender to pathophysiology and clinical presentation of IBS: should management be different in women? Am J Gastroenterol. 2006;101(12 Suppl):S602-609.

58. Mulak A, Waszczuk E, Paradowski L. Irritable bowel syndrome as an interdisciplinary clinical problem. Adv Clin Exp Med. 2008;17:667-675.

59. Ter Horst GJ, Wichmann R, Gerrits M, Westenbroek C, Lin Y. Sex differences in stress responses: focus on ovarian hormones. Physiol Behav. 2009;97(2):239-249.

60. Cain KC, Jarrett ME, Burr RL, Rosen S, Hertig VL, Heitkemper MM. Gender differences in gastrointestinal, psychological, and somatic symptoms in irritable bowel syndrome. Dig Dis Sci. 2009;54(7):1542-1549.

61. Triadafilopoulos G, Finlayson M, Grellet C. Bowel dysfunction in postmenopausal women. Women Health. 1998;27(4):55-66.

62. Gonenne J, Esfandyari T, Camilleri M, Burton DD, Stephens DA, Baxter KL, Zinsmeister AR, et al. Effect of female sex hormone supplementation and withdrawal on gastrointestinal and colonic transit in postmenopausal women. Neurogastroenterol Motil. 2006;18(10):911-918.

63. Keshavarzi Z, et al. The effects of female sex steroids on gastric secretory responses of rat following traumatic brain injury. Iran J Basic Med Sci. 2011;14(3):231-239.

64. Hunt JN, Murray FA. Gastric function in pregnancy. J Obstet Gynaecol Br Emp. 1958;65(1):78-83.

65. Girma K, Janczewska I, Romell B, Seensalu R, Sandin A, Wilander E, Nilsson G. Twenty-four-hour basal and repetitive pentagastrin-stimulated gastric acid secretion in normal and sham-operated rats and in rats after gonadectomy or treatment with estradiol or testosterone. Scand J 
Gastroenterol. 1997;32(7):669-675.

66. Piyachaturawat P, Sretarugsa P, Limlomwongse L, Sahaphong S. Effect of estradiol treatment on the secretion and structure of gastric $\mathrm{H}+$ and pepsin-secreting cells in the rat. Res Commun Chem Pathol Pharmacol. 1983;42(1):81-93.

67. Pfaffl MW, Lange IG, Meyer HH. The gastrointestinal tract as target of steroid hormone action: quantification of steroid receptor mRNA expression (AR, ERalpha, ERbeta and PR) in 10 bovine gastrointestinal tract compartments by kinetic RT-PCR. J Steroid Biochem Mol Biol. 2003;84(2-3):159-166.

68. Kurata JH, Honda GD, Frankl H. The incidence of duodenal and gastric ulcers in a large health maintenance organization. Am J Public Health. 1985;75(6):625-629.

69. Rosenstock SJ, Jorgensen T. Prevalence and incidence of peptic ulcer disease in a Danish County - a prospective cohort study. Gut. 1995;36(6):819-824.

70. Ostensen H, Gudmundsen TE, Bolz KD, Burhol PG, Bonnevie $\mathrm{O}$. The incidence of gastric ulcer and duodenal ulcer in north Norway. A prospective epidemiological study. Scand J Gastroenterol. 1985;20(2):189-192.

71. Bonnevie O. The incidence in Copenhagen County of gastric and duodenal ulcers in the same patient. Scand J Gastroenterol. 1975;10(5):529-536.

72. Wu HC, Tuo BG, Wu WM, Gao Y, Xu QQ, Zhao K. Prevalence of peptic ulcer in dyspeptic patients and the influence of age, sex, and Helicobacter pylori infection. Dig Dis Sci. 2008;53(10):2650-2656.

73. Vessey MP, Villard-Mackintosh L, Painter R. Oral contraceptives and pregnancy in relation to peptic ulcer. Contraception. 1992;46(4):349-357.

74. Keshavarzi Z, Khaksari M. The effects of female sexual steroids on gastric function and barrier resistance of gastrointestinal tract following traumatic brain injury. J Pharm Bioallied Sci. 2015;7(1):75-80.

75. Heitkemper MM, Chang L. Do fluctuations in ovarian hormones affect gastrointestinal symptoms in women with irritable bowel syndrome? Gend Med. 2009;6(Suppl 2):152-167.

76. Li TJ, Yu BP, Dong WG, Luo HS, Xu L, Li MQ. Ovarian hormone modulates 5-hydroxytryptamine 3 receptors mRNA expression in rat colon with restraint stressinduced bowel dysfunction. World J Gastroenterol. 2004;10(18):2723-2726.

77. Lovell RM, Ford AC. Effect of gender on prevalence of irritable bowel syndrome in the community: systematic review and meta-analysis. Am J Gastroenterol. 2012;107(7):991-1000.

78. Adeyemo MA, Spiegel BM, Chang L. Meta-analysis: do irritable bowel syndrome symptoms vary between men and women? Aliment Pharmacol Ther. 2010;32(6):738755 .

79. Chang L, Toner BB, Fukudo S, Guthrie E, Locke GR, Norton NJ, Sperber AD. Gender, age, society, culture, and the patient's perspective in the functional gastrointestinal disorders. Gastroenterology. 2006;130(5):1435-1446.

80. Hang CH, Shi JX, Li JS, Li WQ, Yin HX. Up-regulation of intestinal nuclear factor kappa B and intercellular ad- hesion molecule-1 following traumatic brain injury in rats. World J Gastroenterol. 2005;11(8):1149-1154.

81. Castillo L, Velasco N, Wainstein C, Bugedo G, Hernandez G, Klaassen J, Errandonea M, et al. [Transcranial cytokine gradient and intestinal permeability in acute severe brain injury]. Rev Med Chil. 1999;127(6):639-646.

82. Chen G, Shi J, Ding Y, Yin H, Hang C. Progesterone prevents traumatic brain injury-induced intestinal nuclear factor kappa B activation and proinflammatory cytokines expression in male rats. Mediators Inflamm. 2007;2007:93431.

83. Jin W, Wang H, Ji Y, Hu Q, Yan W, Chen G, Yin H. Increased intestinal inflammatory response and gut barrier dysfunction in Nrf2-deficient mice after traumatic brain injury. Cytokine. 2008;44(1):135-140.

84. Harnish DC. Estrogen receptor ligands in the control of pathogenic inflammation. Curr Opin Investig Drugs. 2006;7(11):997-1001.

85. Pioli PA, Jensen AL, Weaver LK, Amiel E, Shen Z, Shen L, Wira CR, et al. Estradiol attenuates lipopolysaccharide-induced CXC chemokine ligand 8 production by human peripheral blood monocytes. J Immunol. 2007;179(9):6284-6290.

86. Gunal O, Oktar BK, Ozcinar E, Sungur M, Arbak S, Yegen B. Estradiol treatment ameliorates acetic acid-induced gastric and colonic injuries in rats. Inflammation. 2003;27(6):351-359.

87. Stice JP, Knowlton AA. Estrogen, NFkappaB, and the heat shock response. Mol Med. 2008;14(7-8):517-527.

88. Mizushima Y, Wang P, Jarrar D, Cioffi WG, Bland KI, Chaudry IH. Estradiol administration after trauma-hemorrhage improves cardiovascular and hepatocellular functions in male animals. Ann Surg. 2000;232(5):673-679.

89. Yu HP, Hsieh YC, Suzuki T, Choudhry MA, Schwacha MG, Bland KI, Chaudry IH. Mechanism of the nongenomic effects of estrogen on intestinal myeloperoxidase activity following trauma-hemorrhage: up-regulation of the PI-3K/Akt pathway. J Leukoc Biol. 2007;82(3):774780 .

90. Telleria CM, Ou J, Sugino N, Ferguson S, Gibori G. The expression of interleukin- 6 in the pregnant rat corpus luteum and its regulation by progesterone and glucocorticoid. Endocrinology. 1998;139(8):3597-3605.

91. Lan L, Vinci JM, Melendez JA, Jeffrey JJ, Wilcox BD. Progesterone mediates decreases in uterine smooth muscle cell interleukin-1alpha by a mechanism involving decreased stability of IL-1alpha mRNA. Mol Cell Endocrinol. 1999;155(1-2):123-133.

92. Brzozowski T, Konturek PC, Konturek SJ, Drozdowicz D, Kwiecien S, Pajdo R, Bielanski W, et al. Role of gastric acid secretion in progression of acute gastric erosions induced by ischemia-reperfusion into gastric ulcers. Eur J Pharmacol. 2000;398(1):147-158.

93. Khaksari M, Keshavarzi Z, Gholamhoseinian A, Bibak B. The effect of female sexual hormones on the intestinal and serum cytokine response after traumatic brain injury: different roles for estrogen receptor subtypes. Can J Physiol Pharmacol. 2013;91(9):700-707.

94. Vural P, Akgul C, Canbaz M. Effects of hormone re- 
placement therapy on plasma pro-inflammatory and anti-inflammatory cytokines and some bone turnover markers in postmenopausal women. Pharmacol Res. 2006;54(4):298-302.

95. Knoferl MW, Diodato MD, Angele MK, Ayala A, Cioffi WG, Bland KI, Chaudry IH. Do female sex steroids adversely or beneficially affect the depressed immune responses in males after trauma-hemorrhage? Arch Surg. 2000;135(4):425-433.

96. Shimozawa N, Okajima K, Harada N. Estrogen and isoflavone attenuate stress-induced gastric mucosal injury by inhibiting decreases in gastric tissue levels of CGRP in ovariectomized rats. Am J Physiol Gastrointest Liver Physiol. 2007;292(2):G615-619.

97. Sayegh M, Elder JB. Effect of gonadectomy on epidermal growth factor values in the gastrointestinal tract of male and female CD-1 mice. Gut. 1995;36(4):558-563.

98. Zhou ML, Zhu L, Wang J, Hang CH, Shi JX. The inflammation in the gut after experimental subarachnoid hemorrhage. J Surg Res. 2007;137(1):103-108.

99. Shan J, Resnick LM, Liu QY, Wu XC, Barbagallo M, Pang PK. Vascular effects of 17 beta-estradiol in male SpragueDawley rats. Am J Physiol. 1994;266(3 Pt 2):H967-973.
100. Campbell-Thompson M, Reyher KK, Wilkinson LB. Immunolocalization of estrogen receptor alpha and beta in gastric epithelium and enteric neurons. J Endocrinol. 2001;171(1):65-73.

101. Bubenik GA, Blask DE, Brown GM, Maestroni GJ, Pang SF, Reiter RJ, Viswanathan M, et al. Prospects of the clinical utilization of melatonin. Biol Signals Recept. 1998;7(4):195-219.

102. Lindh A, Carlstrom K, Eklund J, Wilking N. Serum steroids and prolactin during and after major surgical trauma. Acta Anaesthesiol Scand. 1992;36(2):119-124.

103. Isomoto $\mathrm{H}$, Inoue $\mathrm{K}$, Kohno $\mathrm{S}$. Interleukin-8 levels in esophageal mucosa and long-term clinical outcome of patients with reflux esophagitis. Scand J Gastroenterol. 2007;42(3):410-411.

104. Wang Y, Hu F, Wang ZJ, Wang GX, Zhang ZH, Xie P, Cui SP. Administration of bone marrow-derived stem cells suppresses cellular necrosis and apoptosis induced by reperfusion of ischaemic kidneys in rats. Chin Med J (Engl). 2008;121(3):268-271.

105. Mulak A, Tache Y, Larauche M. Sex hormones in the modulation of irritable bowel syndrome. World J Gastroenterol. 2014;20(10):2433-2448. 